\title{
Predictive value of pretreatment lymphocyte count in stage II colorectal cancer and in high-risk patients treated with adjuvant chemotherapy
}

\author{
Lei Liang ${ }^{1,2}$, Ji Zhu' ${ }^{1,2,3}$, Huixun Jia ${ }^{1,2}$, Liyong Huang ${ }^{1,2}$, Dawei $\mathrm{Li}^{1,2}$, Qingguo $\mathrm{Li}^{1,2}$, \\ Xinxiang $\mathbf{L i}^{1,2}$ \\ ${ }^{1}$ Department of Colorectal Surgery, Fudan University Shanghai Cancer Center, Shanghai, People's Republic of China \\ ${ }^{2}$ Department of Oncology, Shanghai Medical College, Fudan University, Shanghai, People's Republic of China \\ ${ }^{3}$ Department of Radiation Oncology, Fudan University Shanghai Cancer Center, Shanghai, People's Republic of China \\ Correspondence to: \\ Xinxiang Li, e-mail: Ixx1149@163.com \\ Keywords: pretreatment lymphocyte count, stage II colorectal cancer, prognosis, high risk, adjuvant chemotherapy \\ Received: June 22, $2015 \quad$ Accepted: October 07, 2015 Published: October 20, 2015
}

\section{ABSTRACT}

Pretreatment lymphocyte count (LC) has been associated with prognosis and chemotherapy response in several cancers. The predictive value of LC for stage II colorectal cancer (CRC) and for high-risk patients treated with adjuvant chemotherapy (AC) has not been determined. A retrospective review of prospectively collected data from 1332 consecutive stage II CRC patients who underwent curative tumor resection was conducted. A pretreatment LC value $<1.3 \mathrm{Giga} / \mathrm{L}(28.1 \%, 373 / 1332)$ was defined as low LC. A total of 738 patients (55.4\%) were considered high-risk, $459(62.2 \%)$ of whom received AC. Patients with low LCs had significantly worse 5-year OS $(74.6 \%$ vs. $90.2 \%, p<0.001)$ and DFS $(61.3 \%$ vs. $84.6 \%, p<0.001)$. High-risk patients with low LCs had the poorest DFS $(p<0.001)$. Multivariate analysis indicated that low LC value or combined with high-risk status were both independent prognostic factors $(p<0.001)$. High-risk, AC-treated patients with high LCs had significantly longer DFS than untreated patients (HR, 0.594; 95\% CI, 0.364-0.970; $p=0.035)$. There was no difference or trend for DFS or OS in patients with low LCs, regardless of the use of AC (DFS, $p=0.692$; OS, $p=0.522$ ). Low LC was also independently associated with poorer DFS in high-risk, AC-treated patients (HR, 1.885; 95\% CI, 1.112-3.196; $p=0.019$ ). CONCLUSIONS: Pretreatment LC is an independent prognostic factor for survival in stage II CRC. Furthermore, pretreatment LC reliably predicts chemotherapeutic efficacy in high-risk patients with stage II CRC.

\section{INTRODUCTION}

Colorectal cancer $(\mathrm{CRC})$ is the third most common tumor in men, the second most common tumor in women, and the fourth leading cause of cancer-related death worldwide [1]. For stage II disease, which represents $30-40 \%$ of all resected CRCs, the five-year relative survival rate is $75 \%$, indicating that $25 \%$ of patients relapse and die of their cancer within 5 years of surgery [2].

Several clinical and pathological features, including T4 stage, bowel perforation or clinical bowel obstruction, inadequate lymph node sampling, poorly differentiated histology, lympho-vascular and perineural invasion, have been defined as high-risk factors associated with a worse prognosis for stage II CRC [3]. Current clinical guidelines recommend adjuvant chemotherapy (AC) for such patients to prevent tumor recurrence after curative surgery $[4,5]$. Although these high-risk factors do not reliably predict chemotherapeutic outcome, their presentation is typically associated with a poor prognosis. Therefore, high-risk patients possess the greatest relative benefit from adjuvant treatment [6].

However, the outcome of adjuvant treatment for these patients remains controversial. The MOSAIC trial 
documented a nonsignificant trend toward improved survival in patients with high-risk stage II disease who were treated with adjuvant treatment [7]. Conversely, an analysis of Surveillance, Epidemiology, and End Results (SEER)-Medicare data demonstrated a lack of survival benefit from AC in the same population [8]. Therefore, there is great interest in the elucidation of additional prognostic and predictive biomarkers that can improve outcome through patient classification.

Recent findings have revealed that cancer patient outcomes are not only determined by tumor characteristics but also by patient-related factors. Analysis of the local tumor environment has revealed the role of the immune system in preventing tumor recurrence [9]. Recent studies have reinforced the belief that defective functioning or decreased numbers of lymphocytes reduce the ability of a patient's immune system to mount an effective response to cancer cells. Pretreatment lymphocyte count (LC) is considered a surrogate marker for the level of immunosuppression in patients and has been associated with prognosis in several cancers, including hematological malignancy, breast cancer, and renal cell cancer [10-12]. It has also been suggested that low LC is associated with poor response to chemotherapy or radiotherapy [13, 14], suggesting the important role of LC in survival and clinical treatment response. Therefore, we speculated that pretreatment LC might have important predictive value in the prognosis of stage II CRC and the outcome of high-risk patients treated with AC. To our knowledge, no studies have investigated the value of LC in such patients. Therefore, we conducted a large-scale retrospective cohort study to investigate the prognostic and predictive value of pretreatment LC as a widely available marker for stage II CRC and to identify the stage II CRC patients who will best benefit from the use of AC.

\section{RESULTS}

\section{Patient characteristics}

A total of 1494 patients were retrieved from the database. Of these, 162 were excluded from the study for the following reasons: previous or concomitant other cancers $(n=54)$; complete intestinal obstruction or perforation $(n=48)$; clinical evidence of infection $(n=16)$; preoperative neoadjuvant therapy $(n=14)$; endocrine tumors $(n=5)$; and missing or inaccessible medical files $(n=25)$. Thus, 1332 consecutive patients with stage II CRC were selected for this study. Patients excluded from the analysis were shown in a flow chart (Fig. 1).

Of the 1332 patients, 511 were women (38.4\%) and 821 were men $(61.6 \%)$. The median age for the entire cohort was 60 years (mean, 60.0; range, 17-90). The anatomic locations of the primary tumors were the colon in 688 cases $(51.7 \%)$ and the rectum in 644 cases $(48.3 \%)$. The median LC value was 1.6 Giga/L (mean, 1.71; range,
0.3-5.3). The LC distribution in our patients is shown in Fig. 2. The median follow-up time was 816 days (mean, 924.9 days; range, 8-2480 days). Among the patients, 738 (55.4\%) were considered high-risk and 594 (44.6\%) were deemed low-risk. Within the high-risk group, the most frequent poor prognostic features included T4 tumor (58.3\%), suboptimal lymph node sampling (27.4\%), perineural invasion (21.5\%), lymphovascular invasion $(13.0 \%)$ and poor differentiation $(21.1 \%)$. Approximately 188 patients $(25.5 \%)$ had $>1$ poor prognostic factor. In the high-risk group, 459 (62.2\%) patients received AC. The adjuvant treatments were as follows: a semi-monthly regimen of 5-FU and leucovorin (LV5FU2 regimen, $n=20)$; capecitabine $(n=119)$; a semi-monthly regimen of 5-FU, leucovorin, and oxaliplatin (FOLFOX regimen, $n=132)$; and a regimen of capecitabine and oxaliplatin $(n=189)$.

\section{Determination of $L C$ cutoff value}

To analyze the predictive value of LC for DFS and $\mathrm{OS}$ in patients with stage II CRC, X-tile software was used. This software allowed us to define an optimal cutoff point that defined the LC value required to predict prognosis. For OS, the maximum of $\times 2$ log-rank values of $25.19(p<0.001)$ was achieved when applying an LC of 1.2 as the cutoff value (Fig. 3A), but for DFS, the maximum log-rank statistical value was $25.36(p<0.001)$ when the cutoff value was 1.4 (Fig. 3B). Therefore, we utilized a median of 1.3 as the optimal cutoff value for both OS and DFS in stage II CRC.

\section{Correlation of $\mathrm{LC}$ with clinicopathological characteristics}

Patient baseline characteristics are shown in Table 1. The incidence of low LC was $28.1 \%$ (373/1332). As a continuous variable, low LC correlated with tumor location $(p=0.012)$, T stage $(p=0.025)$ and high risk $(p=0.034)$. As a dichotomous variable, low LC was associated with vessel invasion $(p=0.048)$.

\section{Clinical outcome of LC status or LC status combined with high-risk factors in stage II colorectal cancer}

In Kaplan-Meier analyses, patients with low LCs exhibited decreased postoperative OS and shorter DFS (Fig. 4A, 4B). The 5-year OS and DFS rates of low-LC patients were $74.6 \%$ and $61.3 \%$, respectively, which were significantly lower than those of high-LC patients (OS, 90.2\%; DFS, 84.6\%; $p<0.001$ ). We divided the patients into low- and high-risk groups. Patients with high LC values and a low-risk status had the best prognosis, whereas those with low LC values and a highrisk status had the worst prognosis, with the lowest OS 


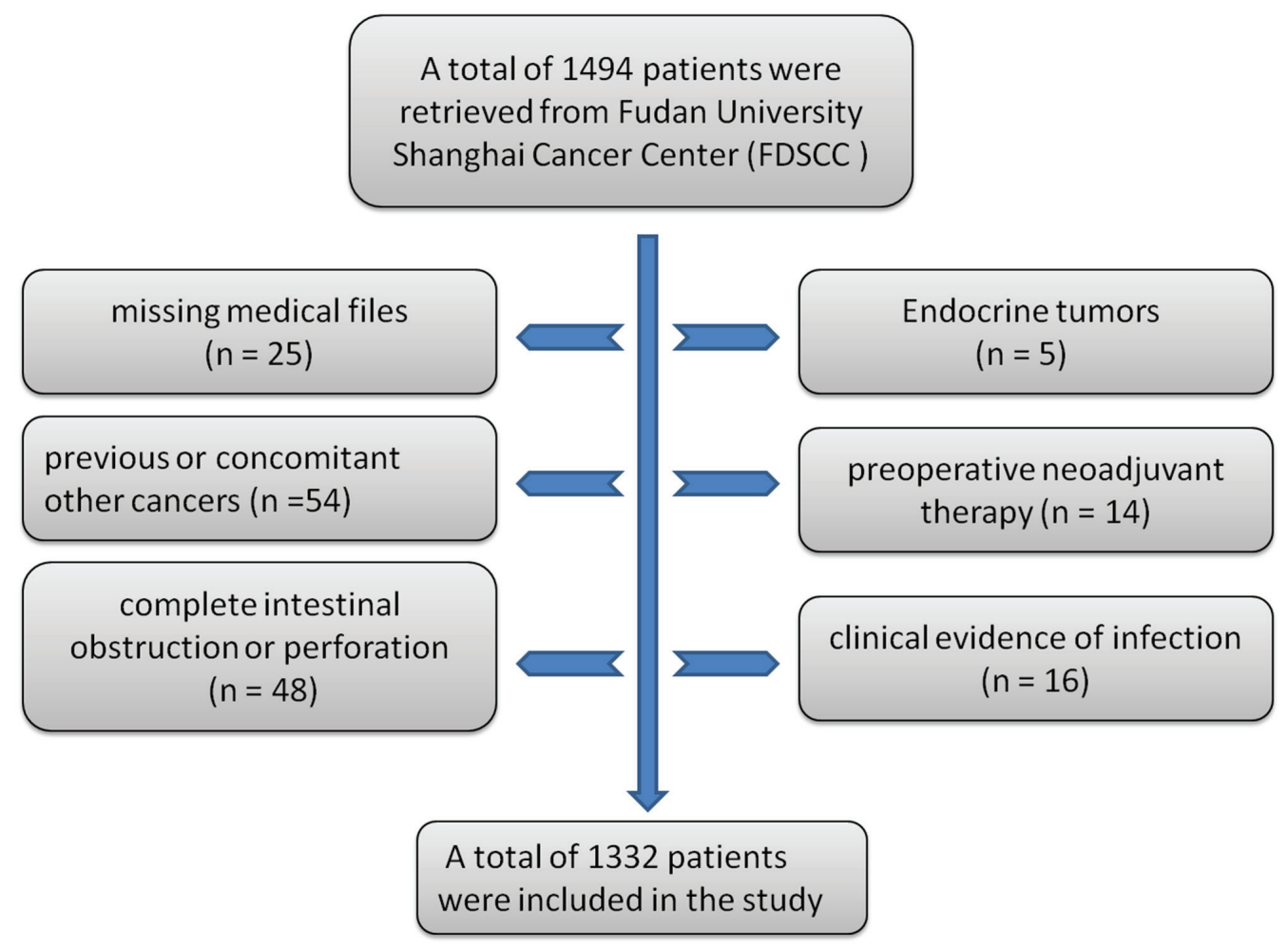

Figure 1: Flow chart of patients excluded from the analysis.

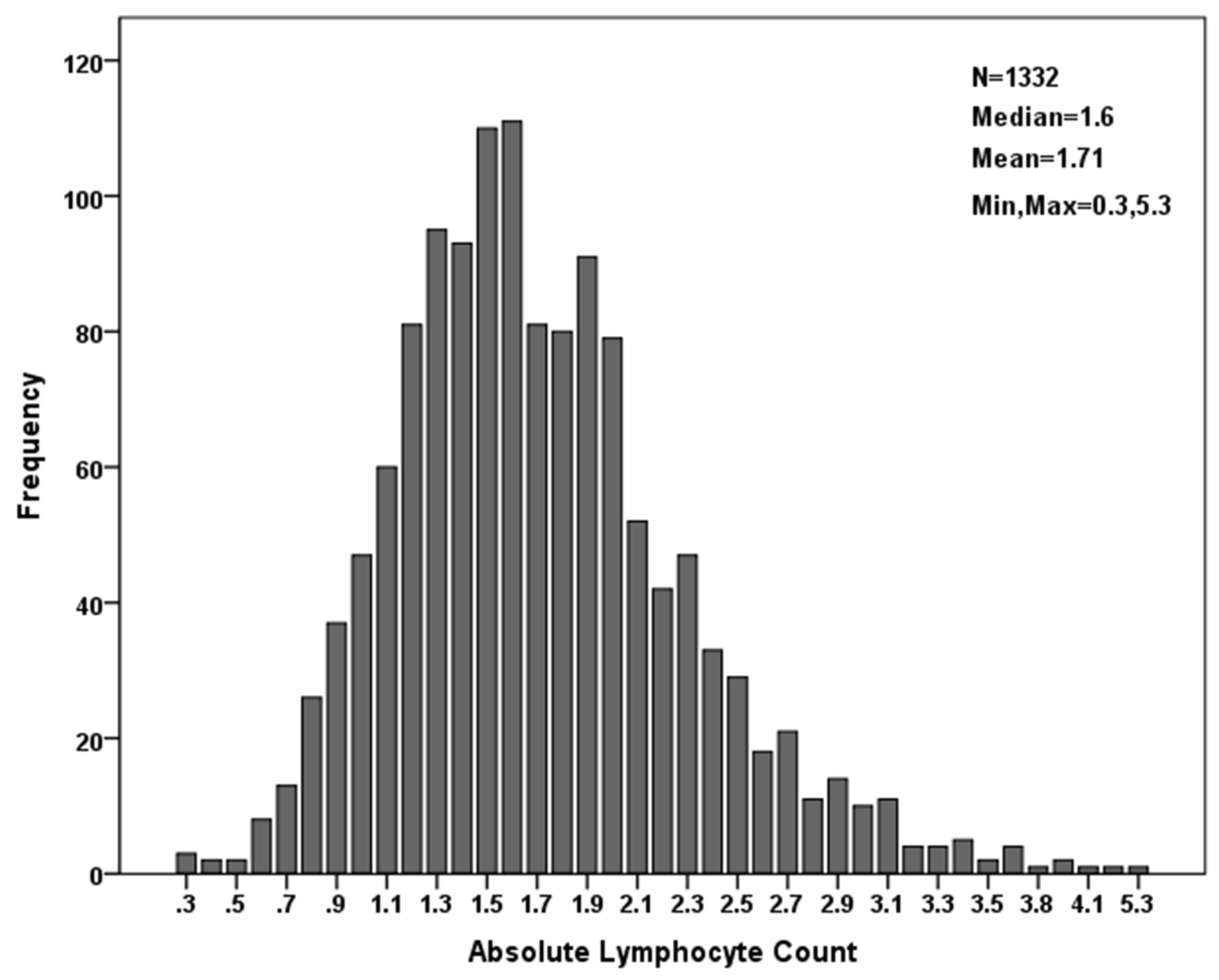

Figure 2: LC distribution within the cohort. 

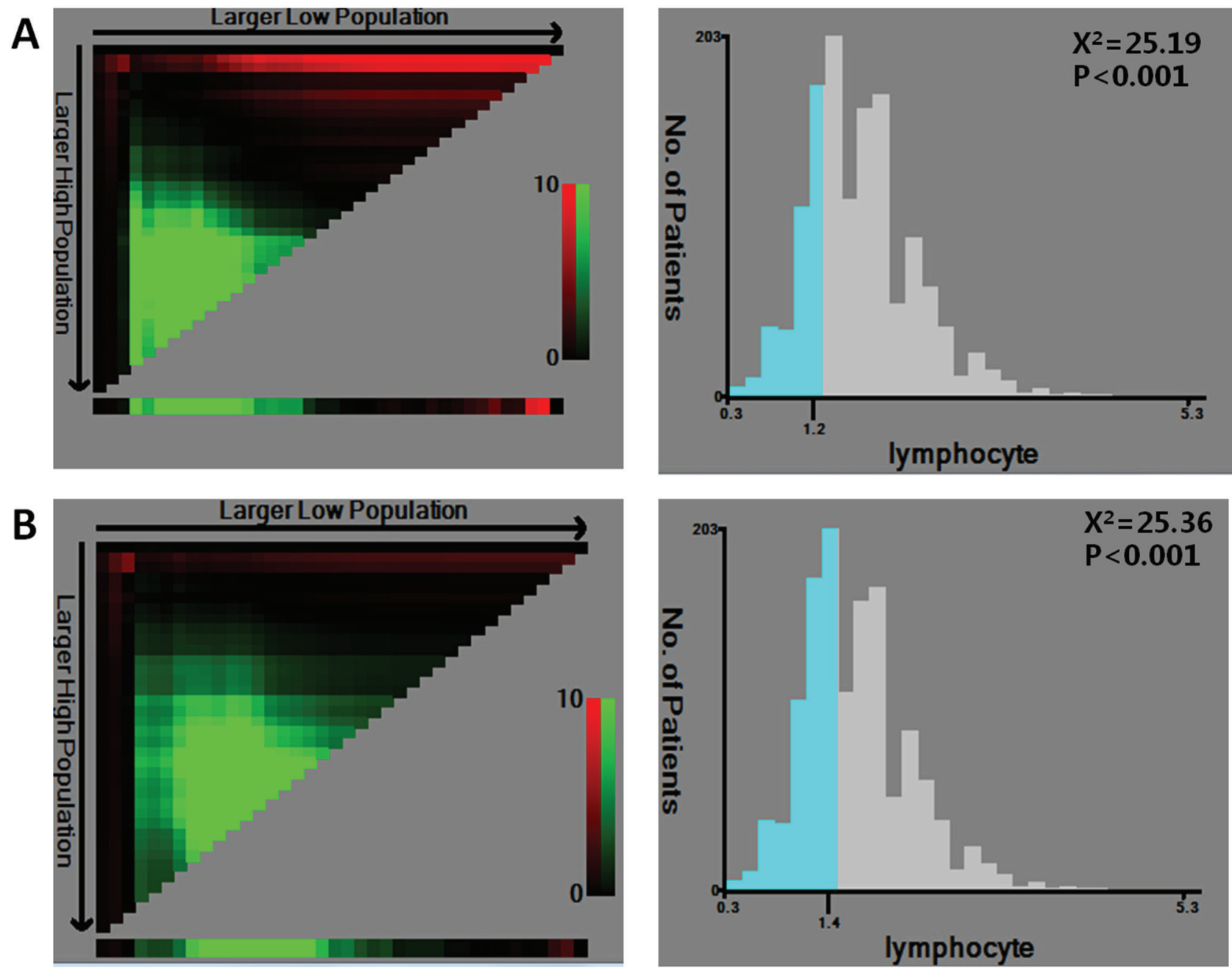

Figure 3: X-tile analysis of survival data within the cohort. X-tile plots of training sets are shown in the left panels. The plot shows the chi-square log-rank values created when the cohort was divided into two groups. The optimal cutoff point highlighted by the black circle in the left panels is shown on a histogram of the entire cohort (right panels). $P$ values were determined using the cutoff point defined in the training subset to parse a separate validation subset. A. The optimal cutoff point for $\operatorname{OS}(\operatorname{LC}=1.2, \mathrm{x} 2=25.19, p<0.001)$. B. The optimal cutoff point for DFS ( $\mathrm{LC}=1.4, \mathrm{x} 2=25.36, p<0.001)$.

and DFS $(p<0.001)$ (Fig. 4C, 4D). Univariate analysis showed that poor DFS was significantly associated with perineural invasion (HR, 2.140; $p<0.001)$, lymph node sampling $<12(\mathrm{HR}, 1.618 ; p=0.011)$, CEA $>5.0 \mu \mathrm{g} / \mathrm{ml}$ $(\mathrm{HR}, 1.682, p=0.002)$ and $\mathrm{LC} \leq 1.3$ (HR, 2.214; $p<0.001)$. Furthermore, $\mathrm{LC} \leq 1.3$ was also associated with poor OS (HR, 2.486; $p<0.001$ ) (Table 2). Multivariable analysis of survival revealed that perineural invasion (HR, $1.957 ; 95 \% \mathrm{CI}, 1.292-2.965 ; p=0.002), \mathrm{CEA}>5.0 \mu \mathrm{g} / \mathrm{ml}$ (HR, 1.488, $p=0.022)$ and LC (HR, 2.090; 95\% CI, $1.493-2.925 ; p<0.001)$ were independent prognostic factors for DFS. Additionally, LC had a significant effect on OS (HR, 2.425; 95\% CI 1.507-3.901; $p<0.001)$. In the multivariable model, the combination of LC and risk factors was also confirmed to be an independent prognostic indicator, especially for DFS $(p<0.001)$ (Table 3$)$.

\section{Predictive value of $L C$ for the use of adjuvant chemotherapy in high-risk patients}

The 738 high-risk patients were divided into two groups: a low-LC $(n=223,30.2 \%)$ and a high-LC group $(n=515,69.8 \%)$. Among the two groups, 136 patients $(61.0 \%)$ and 323 patients $(62.7 \%)$ received AC. The baseline characteristics are described in Table 4 . In the Kaplan-Meier analyses, the patients treated with AC exhibited a nonsignificant improvement in postoperative DFS and OS compared with untreated patients (DFS, $p=0.168$; OS, $p=0.141$; Fig. 5A, 5D). Interestingly, in the high-LC group, the patients treated with AC had a significant DFS advantage compared with those who did not receive AC (5-year DFS rate of $85.3 \%$ vs. $69.4 \%$; HR, 0.594; 95\% CI, 0.364-0.970; $p=0.035$; Fig. 5C). There 
Table 1: Comparison of baseline clinical characteristics based on LC

\begin{tabular}{|c|c|c|c|c|c|c|}
\hline \multirow{2}{*}{ Factors } & \multirow{2}{*}{$\mathbf{N}$} & \multirow{2}{*}{$\frac{\text { Lymphocyte count }}{\text { Mean } \pm \text { SD }}$} & \multirow{2}{*}{$p$-Value } & \multicolumn{2}{|c|}{ Lymphocyte count } & \multirow{2}{*}{$p$ Value } \\
\hline & & & & $\leq 1.3$ & $>1.3$ & \\
\hline Age & & & 0.173 & & & 0.146 \\
\hline$<60$ & 411 & $1.73 \pm 0.57$ & & $103(27.81 \%)$ & $308(32.05 \%)$ & \\
\hline$\geq 60$ & 921 & $1.65 \pm 0.63$ & & $270(72.19 \%)$ & $651(67.85 \%)$ & \\
\hline Sex & & & 0.957 & & & 0.117 \\
\hline Male & 821 & $1.71 \pm 0.57$ & & $217(58.18 \%)$ & $604(62.98 \%)$ & \\
\hline Female & 511 & $1.71 \pm 0.61$ & & $156(41.82 \%)$ & $355(37.02 \%)$ & \\
\hline Location & & & 0.012 & & & 0.179 \\
\hline Rectum & 644 & $1.75 \pm 0.74$ & & $169(45.31 \%)$ & $475(49.53 \%)$ & \\
\hline Colon & 688 & $1.67 \pm 0.61$ & & $204(54.69 \%)$ & $484(50.47 \%)$ & \\
\hline Tumor size $(\mathrm{cm})$ & & & 0.116 & & & 0.200 \\
\hline$\leq 5.0$ & 952 & $1.73 \pm 0.59$ & & $257(68.90 \%)$ & $695(72.47 \%)$ & \\
\hline$>5.0$ & 380 & $1.67 \pm 0.59$ & & $116(31.10 \%)$ & $264(27.53 \%)$ & \\
\hline T stage & & & 0.025 & & & 0.2317 \\
\hline T3 & 902 & $1.74 \pm 0.59$ & & $242(64.87 \%)$ & $660(68.82 \%)$ & \\
\hline $\mathrm{T} 4$ & 430 & $1.66 \pm 0.57$ & & $131(35.13 \%)$ & $299(31.18 \%)$ & \\
\hline Vessel invasion & & & 0.076 & & & 0.048 \\
\hline Negative & 1232 & $1.72 \pm 0.59$ & & $336(90.01 \%)$ & $896(93.43 \%)$ & \\
\hline Positive & 100 & $1.61 \pm 0.60$ & & $37(9.99 \%)$ & $63(6.57 \%)$ & \\
\hline $\begin{array}{l}\text { Lymph node } \\
\text { sampling }\end{array}$ & & & 0.152 & & & 0.105 \\
\hline$<12$ & 201 & $1.66 \pm 0.59$ & & $66(17.69 \%)$ & $135(14.08 \%)$ & \\
\hline$\geq 12$ & 1131 & $1.72 \pm 0.59$ & & $307(82.31 \%)$ & $824(85.92 \%)$ & \\
\hline $\begin{array}{l}\text { Perineural } \\
\text { invasion }\end{array}$ & & & 0.501 & & & 0.456 \\
\hline Negative & 1171 & $1.72 \pm 0.59$ & & $324(86.86 \%)$ & $847(88.32 \%)$ & \\
\hline Positive & 161 & $1.68 \pm 0.59$ & & $49(13.14 \%)$ & $112(11.68 \%)$ & \\
\hline Grade & & & 0.493 & & & 0.365 \\
\hline Well & 242 & $1.75 \pm 0.58$ & & $59(15.78 \%)$ & $183(19.10 \%)$ & \\
\hline Moderate & 988 & $1.71 \pm 0.59$ & & $285(76.47 \%)$ & $703(73.28 \%)$ & \\
\hline Poor & 102 & $1.69 \pm 0.57$ & & $29(7.75 \%)$ & $73(7.62 \%)$ & \\
\hline CEA & & & 0.264 & & & 0.056 \\
\hline$\leq 5.0$ & 800 & $1.72 \pm 0.57$ & & $213(60.34 \%)$ & $587(66.25 \%)$ & \\
\hline$>5.0$ & 439 & $1.68 \pm 0.60$ & & $140(39.66 \%)$ & $299(33.75 \%)$ & \\
\hline Risk factor & & & 0.034 & & & 0.075 \\
\hline No & 594 & $1.75 \pm 0.60$ & & $152(40.75 \%)$ & $442(46.09 \%)$ & \\
\hline Yes & 738 & $1.68 \pm 0.58$ & & $221(59.25 \%)$ & $517(53.91 \%)$ & \\
\hline
\end{tabular}



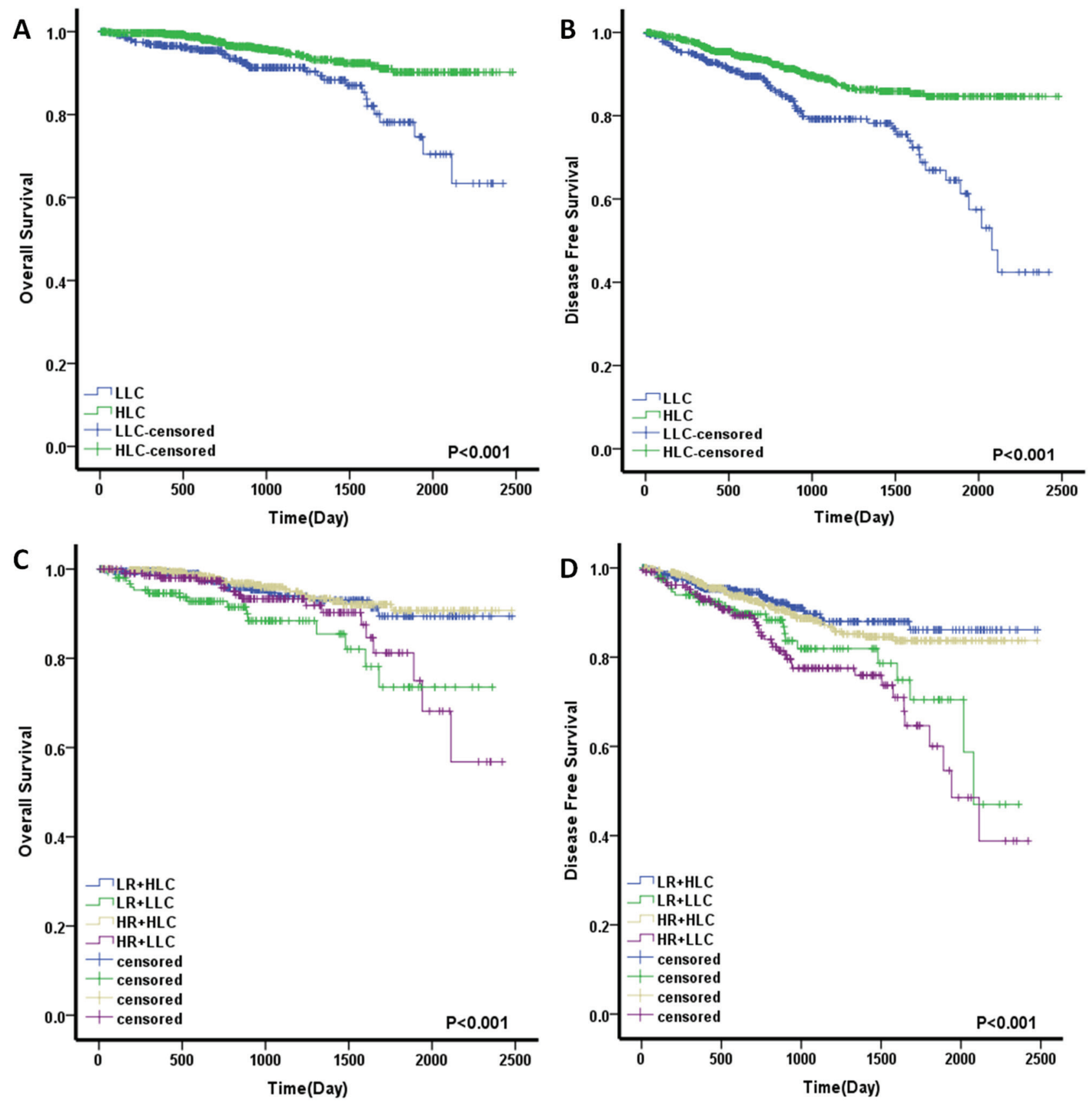

Figure 4: Prognostic significance of $L C$ and $L C$ combined with high-risk factors for stage II colorectal cancer patients assessed by Kaplan-Meier analyses. A. A low LC value was significantly associated with a worse OS. B. A low LC value was significantly associated with a worse DFS. C. LC combined with high-risk factors for OS. D. LC combined with high-risk factors for DFS. The four subgroups were divided according to combinations of LC status and high-risk factors. Low LC, LLC; High LC, HLC; High risk, HR; Low risk, LR.

was also a nonsignificant $\mathrm{OS}$ benefit for the $\mathrm{AC}$ group (88.2\% vs. $82.4 \%$; HR, $0.591 ; 95 \%$ CI, $0.285-1.225$; $p=0.153$; Fig. 5F). It is notable that there were no differences in either DFS or OS in the low-LC patients regardless of receipt of AC (for DFS: HR, 1.141; 95\% CI, $0.594-2.189 ; p=0.692$; for OS: HR, $0.738 ; 95 \%$ CI, $0.290-1.876 ; p=0.522$; Fig. 5B, 5E). In order to exclude potentially confounding factors, we compared the baseline of two groups. No obvious differences were noted in sex, tumor location and risk factors except for age between the patients received $\mathrm{AC}$ or not. Given the recent evidence suggesting that the benefits of $\mathrm{AC}$ might differ based on age [8], we further explored for effect modification by dichotomizing the cohort into elderly patients (aged $\geq 70$ years) and younger patients (aged $<70$ years). In the high-LC group, there was a nonsignificant 
Table 2: Univariate analyses of factors associated with overall survival and disease-free survival

\begin{tabular}{|c|c|c|c|c|}
\hline \multirow[b]{2}{*}{ Variable } & \multicolumn{2}{|c|}{ Disease-free survival } & \multicolumn{2}{|c|}{ Overall survival } \\
\hline & $\begin{array}{c}\text { Hazard ratio } \\
\text { (95\% CI) }\end{array}$ & $p$ Value & $\begin{array}{c}\text { Hazard ratio } \\
(95 \% \mathrm{CI})\end{array}$ & $p$ Value \\
\hline Sex (female vs. male) & $1.192(0.864-1.644)$ & 0.284 & $1.021(0.640-1.629)$ & 0.930 \\
\hline Age, y (<60 vs. $\geq 60)$ & $0.791(0.551-1.135)$ & 0.203 & $0.500(0.240-1.043)$ & 0.064 \\
\hline Location (colon vs. rectum) & $0.939(0.683-1.291)$ & 0.700 & $0.825(0.522-1.305)$ & 0.411 \\
\hline Tumor size $(\mathrm{cm} ; \leq 5$ vs. $>5)$ & $0.964(0.675-1.375)$ & 0.838 & $0.778(0.480-1.259)$ & 0.307 \\
\hline T stage (T4 vs. T3) & $1.365(0.985-1.891)$ & 0.061 & $1.454(0.913-2.315)$ & 0.115 \\
\hline Vessel invasion (positive vs. negative) & $1.413(0.853-2.340)$ & 0.179 & $1.448(0.721-2.909)$ & 0.298 \\
\hline Perineural invasion (positive vs. negative) & $2.140(1.448-3.164)$ & $<0.001$ & $1.685(0.925-3.070)$ & 0.088 \\
\hline Lymph node sampling $(<12$ vs. $\geq 12)$ & $1.618(1.118-2.342)$ & 0.011 & $1.156(0.661-2.020)$ & 0.611 \\
\hline Tumor differentiation (III vs. I-II) & $1.013(0.723-1.418)$ & 0.941 & $1.399(0.869-2.251)$ & 0.167 \\
\hline $\mathrm{CEA}(\mu \mathrm{g} / \mathrm{ml} ;>5.0 \mathrm{vs} \leq 5.0)$ & $1.682(1.203-2.352)$ & 0.002 & $2.107(1.317-3.371)$ & 0.002 \\
\hline $\mathrm{LC}(\leq 1.3$ vs. $>1.3)$ & $2.214(1.607-3.051)$ & $<0.001$ & $2.486(1.575-3.926)$ & $<0.001$ \\
\hline \multicolumn{5}{|l|}{ Combination of LC and risk factor } \\
\hline I versus II & $0.444(0.297-0.664)$ & $<0.001$ & $0.521(0.269-1.012)$ & 0.054 \\
\hline I versus III & $0.809(0.491-1.333)$ & 0.406 & $1.520(0.783-2.952)$ & 0.216 \\
\hline I versus IV & $0.378(0.239-0.597)$ & $<0.001$ & $0.456(0.244-0.851)$ & 0.014 \\
\hline
\end{tabular}

NOTE: Univariate analysis, Cox proportional hazards regression model. I, high LC /low risk; II, low LC/low risk; III, high LC/high risk; IV, low LC/high risk. Abbreviation: 95\% CI, 95\% confidence interval

Table 3: Multivariable analyses of factors associated with overall survival and disease-free survival

\begin{tabular}{|c|c|c|c|c|}
\hline \multirow[b]{2}{*}{ Variable } & \multicolumn{2}{|c|}{ Disease-free survival } & \multicolumn{2}{|c|}{ Overall survival } \\
\hline & $\begin{array}{c}\text { Hazard ratio } \\
(95 \% \text { CI })\end{array}$ & $p$ Value & $\begin{array}{c}\text { Hazard ratio } \\
(95 \% \text { CI })\end{array}$ & $p$ Value \\
\hline Age, y (<60 vs. $\geq 60)$ & $0.845(0.542-1.236)$ & 0.365 & $0.546(0.266-1.116)$ & 0.095 \\
\hline T stage (T4 vs. T3) & $1.217(0.859-1.725)$ & 0.269 & $1.228(0.749-2.011)$ & 0.415 \\
\hline Vessel invasion (positive vs. negative) & $1.168(0.656-1.890)$ & 0.438 & $1.125(0.535-2.365)$ & 0.755 \\
\hline Perineural invasion (positive vs. negative) & $1.957(1.292-2.965)$ & 0.002 & $1.527(0.812-2.871)$ & 0.189 \\
\hline Lymph node sampling ( $<12$ vs. $\geq 12$ ) & $1.460(0.986-2.163)$ & 0.059 & $1.084(0.605-1.941)$ & 0.786 \\
\hline $\mathrm{CEA}(\mu \mathrm{g} / \mathrm{ml} ;>5.0 \mathrm{vs} \leq 5.0)$ & $1.488(1.059-2.091)$ & 0.022 & $1.794(1.112-2.893)$ & 0.017 \\
\hline $\mathrm{LC}(\leq 1.3$ vs. $>1.3)$ & $2.090(1.493-2.925)$ & $<0.001$ & $2.425(1.507-3.901)$ & $<0.001$ \\
\hline \multicolumn{5}{|l|}{ Combination of LC and risk factor } \\
\hline I versus II & $0.485(0.297-0.799)$ & 0.004 & $0.626(0.328-1.265)$ & 0.215 \\
\hline I versus III & $0.966(0.585-1.632)$ & 0.895 & $1.735(0.905-3.370)$ & 0.116 \\
\hline I versus IV & $0.465(0.308-0.720)$ & $<0.001$ & $0.488(0.252-0.910)$ & 0.025 \\
\hline
\end{tabular}

NOTE: Multivariable analysis, Cox proportional hazards regression model. I, high LC /low risk; II, low LC/low risk; III, high LC/high risk; IV, low LC/high risk. Abbreviation: 95\% CI, 95\% confidence interval 
Table 4: Comparison of baseline clinical characteristics in high-risk patients divided by LC status

\begin{tabular}{|c|c|c|c|c|c|c|}
\hline \multirow{2}{*}{ Variable } & \multicolumn{2}{|c|}{ LC $\leq 1.3$ Adjuvant chemotherapy } & \multirow{2}{*}{$p$} & \multicolumn{2}{|c|}{ LC $>1.3$ Adjuvant chemotherapy } & \multirow{2}{*}{$P$} \\
\hline & YES & NO & & YES & NO & \\
\hline Mean age, years & $59.71 \pm 1.02$ & $66.02 \pm 1.36$ & $<0.001$ & $57.48 \pm 0.61$ & $63.05 \pm 0.92$ & $<0.001$ \\
\hline Age $\geq 70(\%)$ & 15.65 & 41.53 & & 13.73 & 38.13 & \\
\hline Sex & & & 0.675 & & & 0.636 \\
\hline Male & $76(55.88 \%)$ & $51(58.62 \%)$ & & $202(62.54 \%)$ & $121(63.02 \%)$ & \\
\hline Female & $60(44.12 \%)$ & $36(41.38 \%)$ & & $121(37.46 \%)$ & $71(36.98 \%)$ & \\
\hline Location & & & 0.881 & & & 0.702 \\
\hline Colon & $93(68.38 \%)$ & $59(67.82 \%)$ & & $207(64.09 \%)$ & $120(62.50 \%)$ & \\
\hline Rectum & $43(31.62 \%)$ & $28(32.18 \%)$ & & $116(35.91 \%)$ & $72(37.50 \%)$ & \\
\hline Risk factor & & & 0.994 & & & 0.603 \\
\hline Single & $98(72.06 \%)$ & $61(70.11 \%)$ & & $248(76.78 \%)$ & $142(73.96 \%)$ & \\
\hline Two & $31(22.79 \%)$ & $20(22.99 \%)$ & & $63(19.50 \%)$ & $44(22.92 \%)$ & \\
\hline Three or more & $7(5.15 \%)$ & $6(6.90 \%)$ & & $12(3.72 \%)$ & $6(3.12 \%)$ & \\
\hline Overall & 136 & 87 & & 323 & 192 & \\
\hline
\end{tabular}
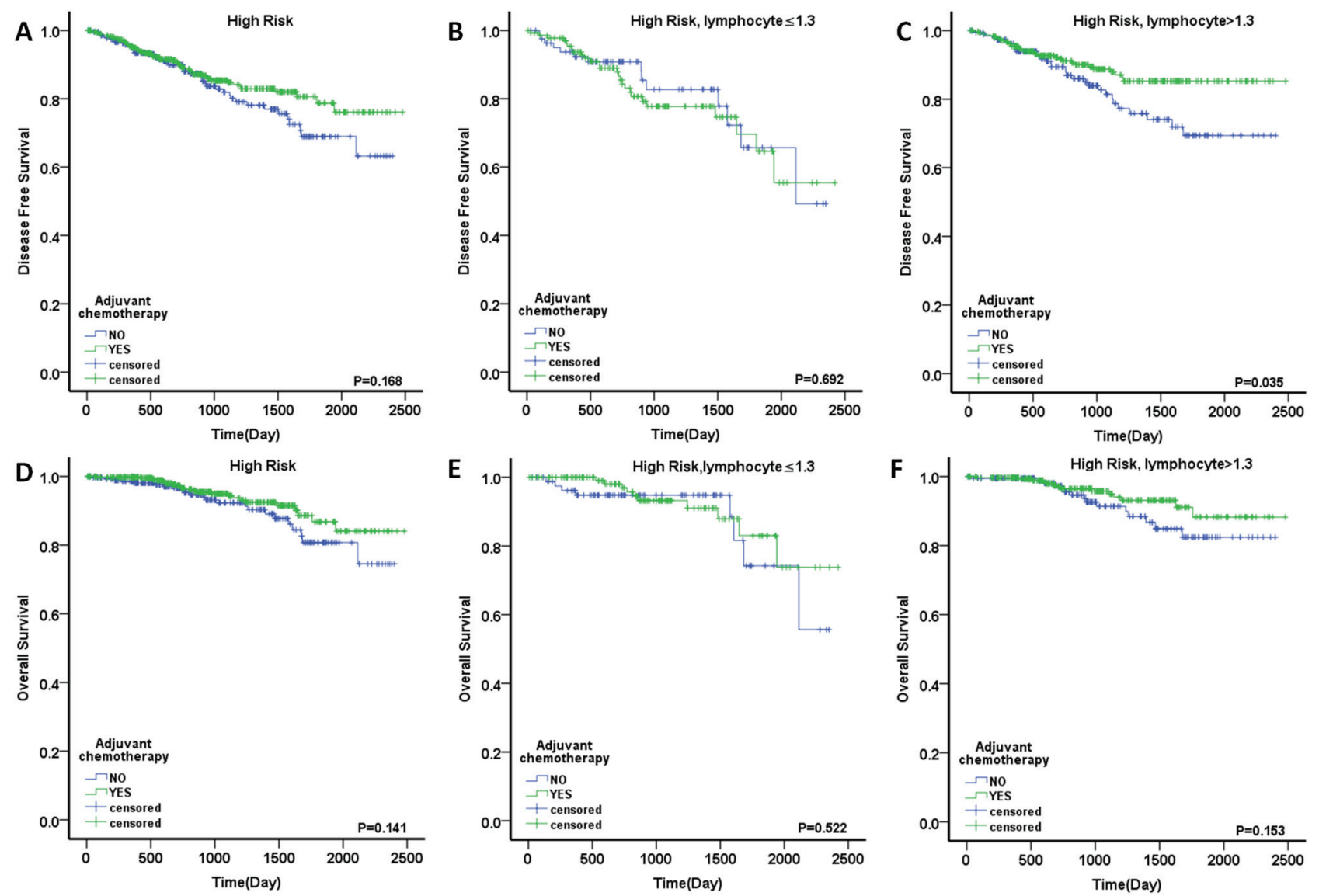

Figure 5: Outcome of adjuvant chemotherapy in stage II colorectal cancer. DFS in the patients with A. high risk, B. high risk and $\mathrm{LC} \leq 1.3, \mathbf{C}$. high risk and $\mathrm{LC}>1.3$; OS in the patients with $\mathbf{D}$. high risk, E. high risk and LC $\leq 1.3$ and $\mathbf{F}$. high risk and LC $>1.3$. 
DFS advantage in both younger and elderly patients treated with AC (for younger patients: HR, 0.704; 95\% CI, $0.375-1.318 ; p=0.273$; for elderly patients: HR, 0.717; 95\% CI, 0.294-1.748; $p=0.464$; Fig. 6A, 6B). However, no obvious DFS improvement was found in the low-LC group, especially for the younger patients (for younger patients: HR, 1.386; 95\% CI, 0.561-3.426; $p=0.480$; for elderly patients: HR, $0.665 ; 95 \% \mathrm{CI}$, $0.198-2.233 ; p=0.509$; Fig. 6C, 6D). Next, we evaluated individual factors associated with poor prognosis in the high-risk patients. The patients with T4 tumors demonstrated significant improvements in DFS following

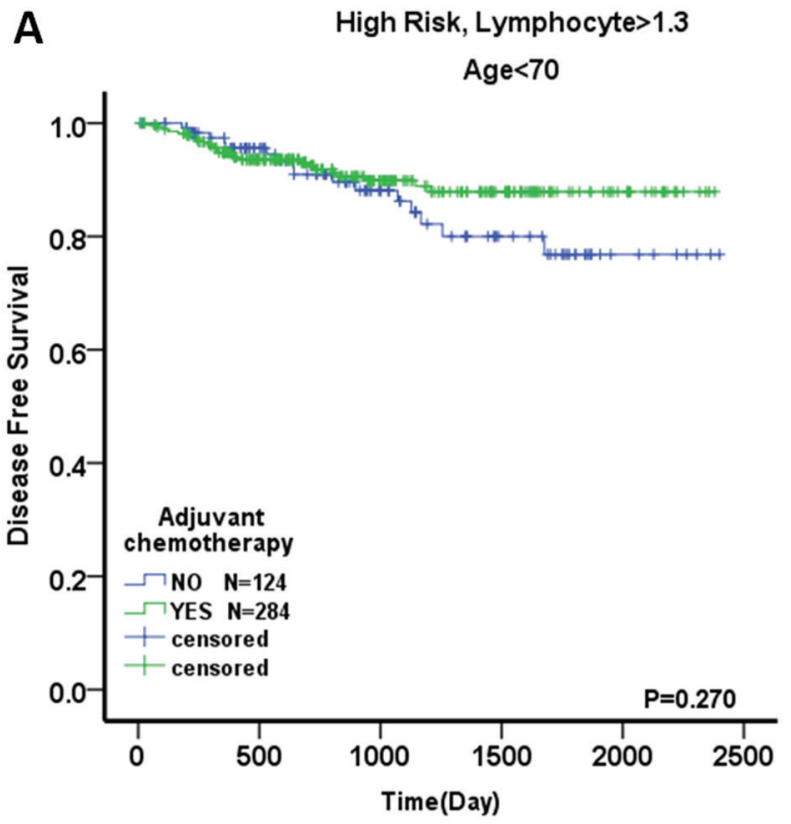

C

High Risk,Lymphocyte $\leq 1.3$

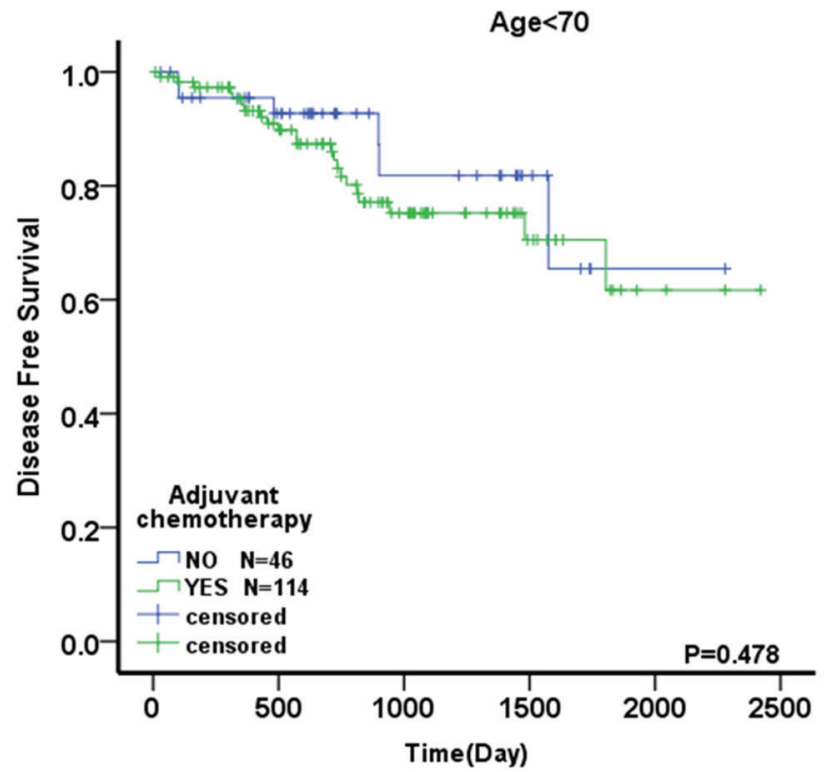

the use of AC both in the high-risk group and the group with high LC. (HR, 0.525; 95\% CI, 0.315-0.876; $p=0.014$; and HR, $0.442 ; 95 \%$ CI, 0.227-0.860; $p=0.013$, respectively; Table 5).

\section{Prognostic value of LC in high-risk patients treated with adjuvant chemotherapy}

To evaluate the prognostic value of LC status in high-risk patients treated with AC,we used Kaplan-Meier to estimate the DFS and OS.Patients with high LC had a significant DFS advantage compared with those with
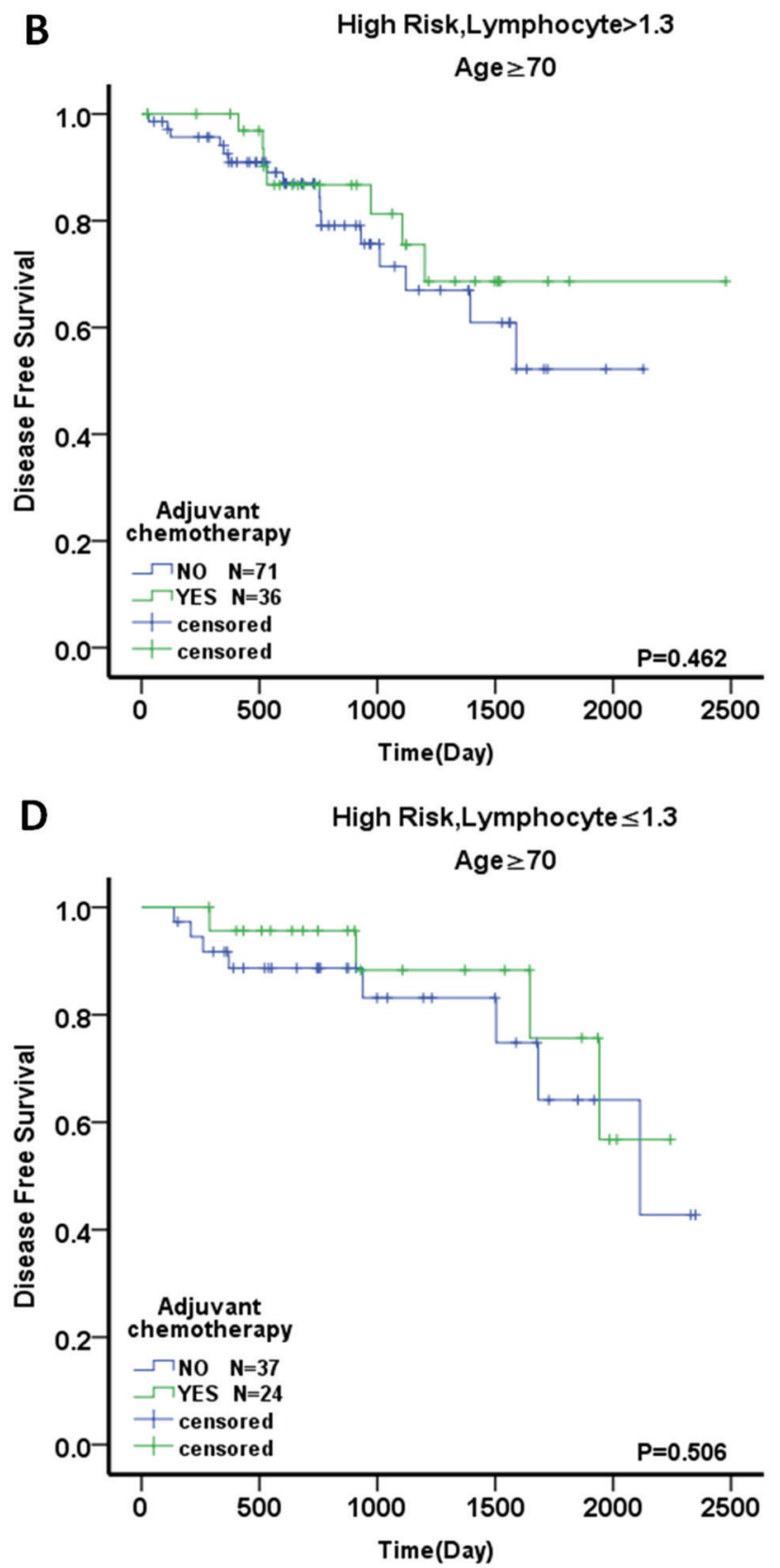

Figure 6: Outcome of adjuvant chemotherapy in stage II colorectal cancer divided by age. DFS in the patients with A. high risk, LC $>1.3$ and age $<70$, B. high risk, $\mathrm{LC}>1.3$ and age $\geq 70$, C. high risk, LC $\leq 1.3$ and age $<70$, and $\mathbf{D}$. high risk, LC $\leq 1.3$ and age $\geq 70$. 
Table 5: Univariate analysis of the effect of adjuvant chemotherapy on outcomes, stratified by specific risk subgroups

\begin{tabular}{|c|c|c|c|c|}
\hline \multirow{2}{*}{ Variable } & \multicolumn{2}{|c|}{ Disease-free survival } & \multicolumn{2}{|l|}{ Overall survival } \\
\hline & Hazard ratio $(95 \% \mathrm{CI})$ & $p$ Value & Hazard ratio (95\% CI) & $p$ Value \\
\hline High risk $(n=738)$ & $0.755(0.513-1.113)$ & 0.156 & $0.645(0.364-1.143)$ & 0.133 \\
\hline Poorly differentiated tumor $(n=156)$ & $0.670(0.305-1.471)$ & 0.319 & $0.418(0.122-1.433)$ & 0.165 \\
\hline Vessel invasion positive $(n=96)$ & $0.675(0.248-1.831)$ & 0.440 & $0.989(0.263-3.719)$ & 0.988 \\
\hline Perineural invasion positive $(n=159)$ & $0.757(0.375-1.527)$ & 0.437 & $0.772(0.258-2.306)$ & 0.643 \\
\hline Lymph nodes sampled <12 $(n=201)$ & $0.787(0.407-1.522)$ & 0.477 & $0.703(0.263-1.876)$ & 0.481 \\
\hline $\mathrm{T} 4(n=430)$ & $0.525(0.315-0.876)$ & 0.014 & $0.548(0.264-1.140)$ & 0.107 \\
\hline High risk $\mathrm{LC}>1.3(n=515)$ & $0.594(0.364-0.970)$ & 0.035 & $0.591(0.285-1.225)$ & 0.153 \\
\hline Poorly differentiated tumor $(n=113)$ & $0.559(0.188-1.667)$ & 0.297 & $0.412(0.069-2.465)$ & 0.331 \\
\hline Vessel invasion positive $(n=62)$ & $0.745(0.210-2.646)$ & 0.649 & $0.924(0.186-4.590)$ & 0.923 \\
\hline Perineural invasion positive $(n=110)$ & $0.543(0.230-1.281)$ & 0.163 & $0.785(0.210-2.933)$ & 0.719 \\
\hline Lymph nodes sampled <12 $(n=110)$ & $0.947(0.409-2.193)$ & 0.899 & $0.789(0.228-2.731)$ & 0.709 \\
\hline $\mathrm{T} 4(n=293)$ & $0.442(0.227-0.860)$ & 0.013 & $0.467(0.183-1.235)$ & 0.127 \\
\hline
\end{tabular}

low LC(3-year DFS rate of $88.7 \%$ vs. $77.7 \% 6$-year DFS rate of $85.3 \%$ vs $55.4 \%$ ) (Fig. 7A, 7B).In univariate and multivariate Cox regression models, Low LC was significantly associated with poorer DFS (HR, 1.978; 95\% CI, 1.178-3.319; $p=0.010$ ). Other DFS prognostic variables are presented in Table 6 and include perineural invasion ( $p=0.038)$, number of lymph nodes sampled $(p=0.013)$ and additional risk factors $(p=0.018)$. Only the patients with two or more poor prognostic factors were associated with a worse OS $(p=0.037)$. The chemotherapy regimen was not found to be associated with either DFS or OS. In the multivariate analyses, low LC (HR, 1.885; 95\% CI, 1.112-3.196; $p=0.019$ ), perineural invasion (HR, $1.965 ; 95 \% \mathrm{CI}, 1.024-3.770 ; p=0.042)$ and number of lymph nodes sampled (HR, 1.964; $95 \%$ CI, 1.105-3.493; $p=0.021$ ) were independent prognostic factors for DFS. Additional risk factors were found to be independently associated with OS, with HR $=2.290,95 \%$ $\mathrm{CI}=1.015-5.167$, and $p=0.046$ (Table 6).

\section{DISCUSSION}

In the present study, we performed a large-scale retrospective cohort study on patients with stage II $\mathrm{CRC}$ and described three major findings. First, $\mathrm{LC}$ is an independent poor prognostic factor for DFS and OS in stage II CRC. Second, by comparing high-risk patients who did and did not receive $\mathrm{AC}$, we found that patients with low LC did not benefit from AC, whereas patients with high LC had a significant DFS advantage, especially patients with T4 stage disease. Finally, low LC was also associated with poor prognosis in high-risk patients treated with AC. To our knowledge, this is the first study to determine the predictive value of pretreatment LC in stage II CRC and high-risk patients treated with AC.

In recent years, several reports have documented a correlation between peripheral LC and survival in patients with various types of malignancies, including pancreatic ductal adenocarcinoma, esophageal squamous cell carcinoma, and lung cancer [16-18]. However, LC cutoff values vary among different cancers, ranging from 1.0 to $1.9[14,16-18]$. Therefore, in this study, X-tile software was used to analyze the optimum cutoff value of LC for stage II CRC. The data showed that a median LC of 1.3 was the optimal cutoff value for OS and DFS, and this value was also employed in previous studies $[12,19]$.

Next, we evaluated the efficacy of LC for predicting postoperative survival. LC was associated with vessel invasion and high-risk factors, which is concordant with data from Jian Zhang et al [20], who found that low LC was related to lymphatic invasion in non-small cell lung cancer. Furthermore, we demonstrated that patients with low LCs had significantly decreased postoperative 5 -year OS (74.6\% vs. 90.2\%, $p<0.001)$ and shorter DFS $(61.3 \%$ vs. $84.6 \%, p<0.001)$ compared to those with high LCs. In multivariate analysis, low LC was a significant and strong independent poor predictive factor for DFS $(p<0.001)$ and OS $(p<0.001)$. It is well known that the high-risk factors for stage II CRC include perforation, T4 tumors, suboptimal lymph node sampling, poor differentiation, colonic obstruction, and lymphovascular or perineural invasion $[3,5]$. In the current study, we excluded the impact of perforation and colonic obstruction on baseline LC. Among the remaining features, perineural invasion (HR, 2.140; $p<0.001)$ and suboptimal lymph node sampling $(\mathrm{HR}, 1.618 ; p=0.011)$ 

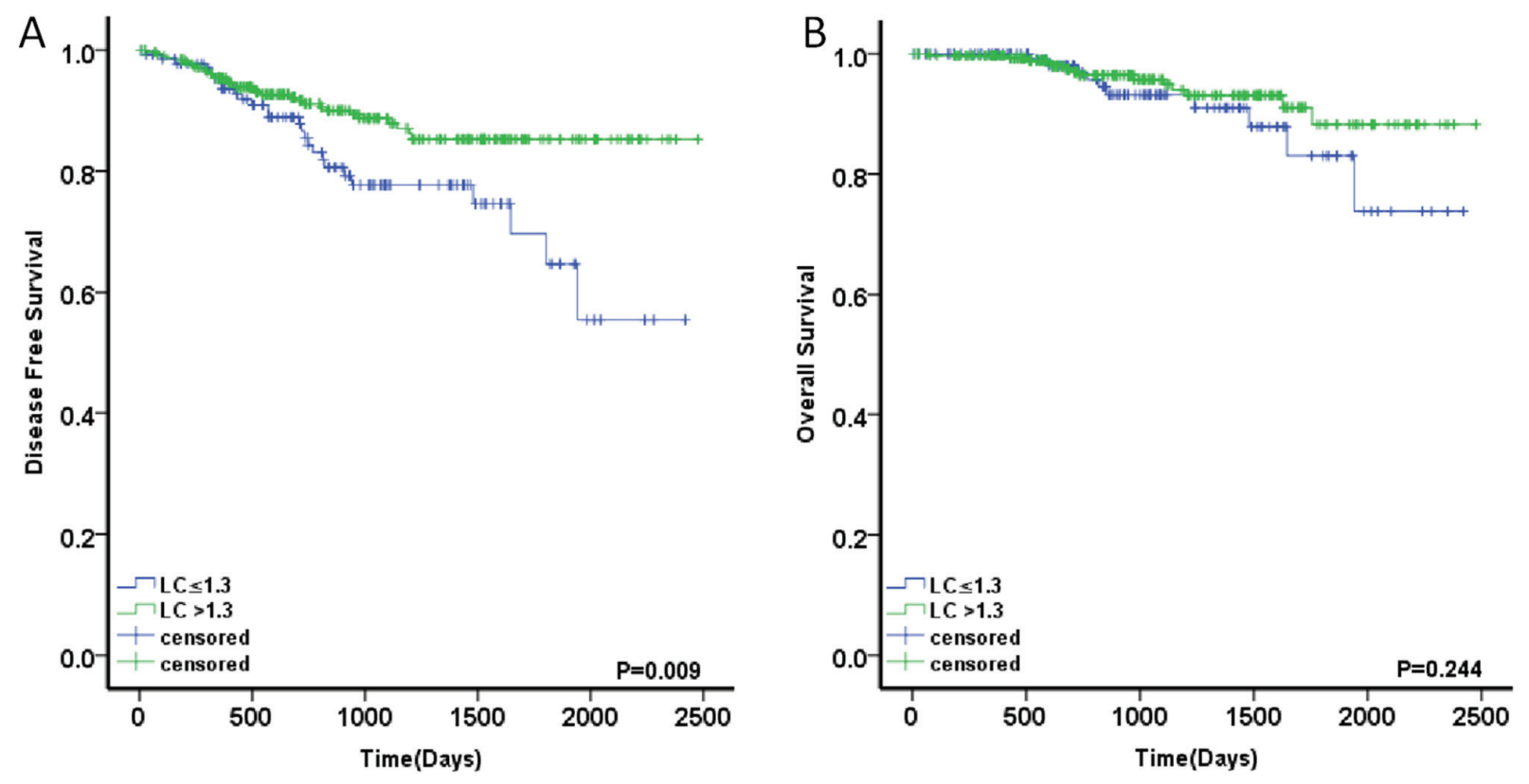

Figure 7: Prognostic value of LC in high-risk patients treated with adjuvant chemotherapy. A. DFS in the patients with $\mathrm{LC} \leq 1.3$ or $>1.3$ B. OS in the patients with $\mathrm{LC} \leq 1.3$ or $>1.3$.

Table 6: Univariate and multivariable analyses of factors associated with overall survival and disease-free survival of high-risk patients treated with adjuvant chemotherapy

\begin{tabular}{|c|c|c|c|c|}
\hline \multirow{2}{*}{ Variable } & \multicolumn{2}{|c|}{ Disease-free survival } & \multicolumn{2}{|l|}{ Overall survival } \\
\hline & Hazard ratio $(95 \% \mathrm{CI})$ & $p$ Value & Hazard ratio $(95 \% \mathrm{CI})$ & $p$ Value \\
\hline \multicolumn{5}{|l|}{ Univariate Analyses } \\
\hline Sex (female vs. male) & $1.198(0.715-2.007)$ & 0.493 & $1.295(0.581-2.883)$ & 0.527 \\
\hline Age, y (<70vs. $\geq 70)$ & $0.714(0.370-1.378)$ & 0.316 & $0.417(0.173-1.007)$ & 0.052 \\
\hline Location (colon vs. rectum) & $0.856(0.582-1.171)$ & 0.715 & $0.765(0.317-1.845)$ & 0.550 \\
\hline Tumor size $(\mathrm{cm} ; \leq 5$ vs. $>5)$ & $1.302(0.702-2.413)$ & 0.402 & $0.707(0.303-1.652)$ & 0.423 \\
\hline T stage (T4 vs. T3) & $1.430(0.854-2.394)$ & 0.174 & $1.213(0.529-2.778)$ & 0.648 \\
\hline Vessel invasion (positive vs. negative) & $1.704(0.884-3.286)$ & 0.112 & $1.754(0.655-4.703)$ & 0.264 \\
\hline Perineural invasion (positive vs. negative) & $1.808(1.035-3.160)$ & 0.038 & $1.784(0.737-4.319)$ & 0.199 \\
\hline Number of lymph nodes (<12 vs. $\geq 12)$ & $1.952(1.154-3.301)$ & 0.013 & $1.068(0.452-2.526)$ & 0.880 \\
\hline Tumor differentiation (III vs. I-II) & $1.051(0.557-1.987)$ & 0.877 & $1.262(0.430-3.703)$ & 0.672 \\
\hline $\mathrm{LC}(\leq 1.3$ vs. $>1.3)$ & $1.978(1.178-3.319)$ & 0.010 & $1.612(0.716-3.631)$ & 0.249 \\
\hline Risk factor (two or more vs. one) & $1.915(1.120-3.273)$ & 0.018 & $2.374(1.053-5.352)$ & 0.037 \\
\hline Chemotherapy (bi-therapy vs. monotherapy) & $0.873(0.449-1.695)$ & 0.688 & $0.637(0.256-1.587)$ & 0.333 \\
\hline \multicolumn{5}{|l|}{ Multivariable Analyses } \\
\hline Age, y (<70 vs. $\geq 70)$ & $0.874(0.446-1.713)$ & 0.695 & $0.436(0.180-1.056)$ & 0.066 \\
\hline Perineural invasion (positive vs. negative) & $1.965(1.024-3.770)$ & 0.042 & & \\
\hline Number of lymph nodes ( $<12$ vs. $\geq 12)$ & $1.964(1.105-3.493)$ & 0.021 & & \\
\hline Risk factor (two or more vs. one) & $1.195(0.636-2.244)$ & 0.579 & $2.290(1.015-5.167)$ & 0.046 \\
\hline $\mathrm{LC}(\leq 1.3$ vs. $>1.3)$ & $1.885(1.112-3.196)$ & 0.019 & & \\
\hline
\end{tabular}


were independent prognostic factors for reduced DFS. Moreover, the combination of LC and risk factor status was also confirmed as an independent prognostic indicator, especially for DFS $(p<0.001)$, and was even stronger than LC alone.

There is substantial evidence that the systemic immune response of a host against a tumor is a vital independent prognostic factor. Solid tumors are generally infiltrated with leukocyte subsets, among which lymphocytes play a major role in the immune response by mediating the immunologic destruction of various cancers [21-23]. In CRC, Jass et al [24] and Ropponen et al [25] noted that conspicuous lymphocytic infiltration along the invasive tumor margin is an independent prognostic factor for improved survival. In most cases, these lymphocytes are either CD4+ or CD8+ T cells [26, 27]. Differentiated $\mathrm{CD} 8+\mathrm{T}$ cell clusters have a pivotal role in tumor growth control via their induction of cytotoxic T-cell killing and apoptosis [28]. The quantity of $\mathrm{CD} 8+\mathrm{T}$ cells that are present significantly correlates with improved diseasespecific survival in CRC [29]. Meanwhile, CD4+ T cells play a central role in orchestrating the immune response to cancer [30]. Although no direct research has demonstrated that peripheral lymphocyte count correlates with the number of tumor-infiltrating lymphocytes, some studies have indicated an association between them. Romano et al [31] found that preoperative treatment with recombinant human IL-2 significantly increased total peripheral blood lymphocytes and CD4 cells, which resulted in higher lymphocyte tumor infiltration. Additionally, Chiba et al [29] observed that the prognostic impact of intraepithelial CD8+ T cells in CRC is more evident when the followup period is longer. Disease-specific survival curves for patients with different levels of intraepithelial CD8+ $\mathrm{T}$ cells are similar during the first 1-2 years of follow-up and subsequently diverge. These survival curves were very similar to the peripheral LC results in our study. Moreover, Pages et al [32] also demonstrated that early metastatic invasion is negatively associated with tumor-infiltrating immune cells, which agreed with our results showing that low peripheral LC was significantly associated with vascular invasion. These results suggest that local immune responses in tumor tissues might not actually be confined to local sites but rather may reflect systemic anti-tumor immune responses. Therefore, lymphocytopenia, as an index of a generalized depressed immune status, might adversely influence survival due to reduced systemic and local host responses to tumors.

The role of $\mathrm{AC}$ is well established in stage III CRC, but its benefit to stage II patients remains controversial. The MOSAIC study demonstrated no improvement in DFS or OS in 899 patients with stage II disease (DFS: HR, $0.84 ; p=0.258$; OS: HR, $1.00 ; p=0.986)$. A trend toward improved outcome was noted among high-risk stage II patients (DFS: HR, 0.72; OS: HR, 0.91; $p=0.648$ ) [7]. Conversely, an analysis of SEER-Medicare data demonstrated a lack of survival benefit from $\mathrm{AC}$ in the same population (HR, 1.03 ; 95\% CI, $0.94-1.15 ; p=0.47$ ) [8]. Therefore, there is considerable interest in elucidating additional predictive biomarkers that could improve outcome through patient classification. It is notable that most prior research has focused on the factors associated with poor prognosis in stage II patients while ignoring host immune status. Ropponen et al [25] confirmed that there is an inverse correlation between the presence of tumor infiltrating lymphocytes and tumor stage in CRC: infiltrating CD8+ $\mathrm{T}$ cells are more prominent during early stages (stages I and II) and decrease in number during advanced stages (stages III and IV). This situation might be a consequence of systemic immune suppression in patients with advanced-stage disease. This possibility in turn suggests that immune status plays an important role in the outcome of early-stage CRC because micrometastases are more amenable to elimination via host immune response. Therefore, in contrast to advanced CRC, more attention should be paid to the combination of immune status and poor prognostic factors when evaluating treatment effect in stage II patients. In the current study, we demonstrated that high-risk patients treated with AC exhibited nonsignificant improvements in DFS and OS (DFS: $p=0.168$, OS: $p=0.141$ ). High-LC patients who received AC had a significant DFS advantage compared to those not treated with AC ( $p=0.035$; HR, 0.594). However, there was no difference or trend in DFS or OS in low-LC patients regardless of the receipt of AC (DFS: $p=0.692$; HR, 1.141; OS: $p=0.522$; HR, 0.738). In multivariate analysis, low LC was independently associated with poorer DFS ( $p=0.019$; HR, 1.885) in high-risk patients treated with AC. The above research supports our hypothesis that patient immune status substantially impacts the outcome of AC. Stage II CRC patients with a normal immune status might gain more benefit from adjuvant treatment than those with a poor immune status, who might derive no benefit, regardless of the presence of high-risk factors.

Some studies have suggested an association between pretreatment lymphopenia and poor cancer survival or poor response to chemotherapy or radiotherapy. Lissoni et al [21] showed that lymphocytopenia prior to chemotherapy is associated with lower treatment efficacy in terms of objective tumor regression rates in patients with metastatic solid tumors. Kitayama et al [33] and Chi Hwan Choi [34] suggested that pretreatment LC was an important determinant of preoperative radiotherapy efficacy in advanced rectal cancer. The mechanism underlying the association between low LC and decreased chemotherapy efficacy is not well understood. The possible reasons are as follows: 1) Chemotherapy might cause lymphocyte depletion and alter the balance of lymphocyte subpopulations [35], which might further decrease LC in patients with lymphocytopenia. Lymphocyte depletion, especially of $\mathrm{T}$ cells, potentially 
compromises the effectiveness of the anti-tumor immune response. 2) Lymphopenia represents an ineffective antitumor immune response against cancer cells/tissues, which leads to tumor recurrence regardless of the receipt of AC. 3) Lymphopenia appears to lead to severe chemotherapyinduced hematological toxicity [13], which results in a significant disadvantage for patients. Collectively, our results suggest that in stage II CRC, AC should be used in high-risk patients with a favorable immune status (LC > 1.3), especially those with stage T4 disease. For high-risk patients with a poor immune status ( $\mathrm{LC} \leq 1.3$ ), AC should not be recommended because it does not benefit survival and potentially leads to severe toxicity.

There are several limitations to the current study. First, although we adopted rigorous inclusion and exclusion criteria, it has been shown that diabetes mellitus and renal and/or hepatic failure might potentially affect lymphocytes [36, 37]. Additionally, anti-diabetic drugs, anti-hypertensive drugs, and/or other medications might potentially affect LC. Therefore, larger prospective studies are needed to confirm these preliminary results. Second, toxicity information is not routinely collected in our database, thereby limiting our ability to explore this aspect in greater detail. Third, different schedules of chemotherapy were used, leading to potential differences in the outcome of AC. However, these limitations should be viewed within the context of the study's strengths, including its population-based nature, generalizability, and relatively large sample of patients with stage II CRC.

In conclusion, our study is the first to demonstrate that pretreatment LC is an independent prognostic factor for survival in stage II CRC patients. Furthermore, pretreatment LC is also an independent prognostic factor for high-risk patients treated with AC. Most importantly, pretreatment LC reliably predicts chemotherapy efficacy in high-risk patients. Therefore, based on its easy attainability, pretreatment LC might be used to select patients with high-risk disease, evaluate intensified therapy, and develop novel agents to improve patient outcome.

\section{PATIENTS AND METHODS}

Clinical data were collected from Fudan University Shanghai Cancer Center (FDSCC), Shanghai, China. The FDSCC dataset was built prospectively and included records of all colorectal cancer patients treated at FDSCC since January, 2006. A total of 1494 patients were retrieved from the database. Patients with the following inclusion criteria were enrolled: 1) hospitalized for primary diagnosis and therapy; 2) CRC confirmed by histopathology with curative primary tumor resection and staged according to TNM criteria (AJCC criteria 2009); 3) stage II disease; 4) preoperative blood test results obtained within 1 week prior to surgery; and 5) all clinical data were available. Patients with the following criteria were excluded: 1) incomplete resection with microscopic or macroscopic residual tumors; 2) previous or concomitant other cancers; 3) absence of detailed information or clinical data; 4) clinical evidence of infection, other inflammation, or hematologic disease, or use of hematology-influencing drugs within one month; 5) preoperative neoadjuvant therapy; 6) complete intestinal obstruction or perforation; and 6) contact lost during follow-up.

The following data were collected from the medical records of each patient: age ( $<60$ and $\geq 60$ years); sex (male or female); tumor size $(\leq 5$ and $>5 \mathrm{~cm})$; tumor location (colon and rectum); T stage (T3 and T4); differentiation (well, moderate, and poor); vessel invasion (negative and positive); perineural invasion (negative and positive); and number of lymph nodes sampled $(<12$ and $\geq 12$ ). Vessel and perineural invasion was recorded according to the results of pathologic reports. The 7 th edition was used to define the $\mathrm{T}$ stage as follows: T3, invasion of the adventitia; T4, invasion of adjacent structures. As part of the physical examinations, peripheral blood was collected before surgery, and peripheral lymphocytes were counted using an automated hematology analyzer (Sysmex XE-5000; Sysmex, Kobe, Japan).

LC cutoff points were produced and analyzed using the X-tile program (http:/www.tissuearray.org/rimmlab/), which identified the cutoff with the minimum $p$ values from log-rank $\times 2$ statistics in terms of survival [15]. The endpoints assessed were disease-free survival (DFS) and overall survival (OS). For assessment of DFS, recurrence was defined as time from operation to development of local, nodal (regional) and distant metastasis. OS was defined as time from operation to date of death.

Patients with stage II disease complicated by T4 tumors, suboptimal lymph node sampling $(<12$ lymph nodes), the presence of lymphovascular or perineural invasion or poor differentiation were categorized as "highrisk". For the high-risk group, the role of postoperative AC is controversial, and adjuvant therapy was not mandatory. The most frequent ACs included 5-fluorouracil (5-FU) and oxaliplatin. In all cases, treatment regimens were based on recommended dosing ranges and schedules. The duration of $\mathrm{AC}$ was 6 months.

Independent $\mathrm{t}$ tests were used to compare the LC as a continuous variable. Chi-square tests were used to determine the significance of differences for patients grouped by LC as a dichotomous variable. Survival curves were generated using Kaplan-Meier estimates, and differences between the curves were analyzed by a logrank test. Cox regression models were built for analysis of risk factors for survival outcomes in CRC patients. Continuous variables, reported as LC, were compared using the Wilcoxon rank-sum test. Multivariate analyses with a Cox proportional hazards model were used to test independence, significance, and hazard discrimination. Covariates included in the model are given in the result 
tables as previously reported. Statistical analyses were performed using the statistical software package SPSS for Windows, version 19 (SPSS Inc., Chicago, IL, USA). A two-tailed $p$ value $<0.05$ was considered significant.

\section{ACKNOWLEDGMENTS}

The authors acknowledge the efforts of the Fudan University Shanghai Cancer Center in the creation of the FDSCC database. The interpretation and reporting of these data are the sole responsibility of the authors. This study was supported by grants from the China Medical Foundation (NO: 201301). The authors thank Zhuzhu Qian for her assistance with survival data collection.

\section{CONFLICTS OF INTEREST}

None of the authors have any conflicts of interest to declare.

\section{Authors' contributions}

LL and JZ contributed equally to this work. LL and XXL conceived and designed the study. JZ and HXJ performed the analyses. LYH and DWL prepared all figures and tables. LL, XXL and JZ wrote the main manuscript. All authors reviewed the manuscript.

\section{REFERENCES}

1. Ferlay, J.Shin, H. R.Bray, F.Forman, D.Mathers, C.Parkin, D. M. Estimates of worldwide burden of cancer in 2008: GLOBOCAN 2008. Int J Cancer, 2010. 127: p. 2893-917.

2. Merkel, S. Wein, A.Gunther,K.Papadopoulos, T.Hohenberger, W.Hermanek, P. High-risk groups of patients with Stage II colon carcinoma. Cancer, 2001.92: p. 1435-43.

3. Benson, A. B., 3rd Schrag, D.Somerfield, M. R.Cohen, A. M.Figueredo, A. T.Flynn, P. J.Krzyzanowska, M. K.Maroun, J.McAllister, P.Van Cutsem, E.Brouwers, M.Charette, M.Haller, D. G. American Society of Clinical Oncology recommendations on adjuvant chemotherapy for stage II colon cancer. Journal of Clinical Oncology, 2004. 22: p. 3408-19.

4. Boland, G. M.Chang, G. J.Haynes, A. B.Chiang, Y. J.Chagpar, R.Xing, Y.Hu, C. Y.Feig, B. W.You, Y. N.Cormier, J. N. Association between adherence to National Comprehensive Cancer Network treatment guidelines and improved survival in patients with colon cancer. Cancer, 2013. 119: p. 1593-601.

5. Schmoll, H. J.Van Cutsem, E.Stein, A.Valentini, V.Glimelius, B.Haustermans, K.Nordlinger, B.van de
Velde, C. J.Balmana, J.Regula, J.Nagtegaal, I. D.BeetsTan, R. G.Arnold, D. et al., ESMO Consensus Guidelines for management of patients with colon and rectal cancer. a personalized approach to clinical decision making. Annals of Oncology, 2012. 23: p. 2479-516.

6. Quah, H. M.Chou, J. F.Gonen, M.Shia, J.Schrag, D.Landmann, R. G.Guillem, J. G.Paty, P. B.Temple, L. K.Wong, W. D.Weiser, M. R. Identification of patients with high-risk stage II colon cancer for adjuvant therapy. Dis Colon Rectum, 2008. 51: p. 503-7.

7. Andre, T.Boni, C.Navarro, M.Tabernero, J.Hickish, T.Topham, C.Bonetti, A.Clingan, P.Bridgewater, J.Rivera, F.de Gramont, A. Improved overall survival with oxaliplatin, fluorouracil, and leucovorin as adjuvant treatment in stage II or III colon cancer in the MOSAIC trial. Journal of Clinical Oncology, 2009. 27: p. 3109-16.

8. O'Connor, E. S.Greenblatt, D. Y.LoConte, N. K.Gangnon, R. E.Liou, J. I.Heise, C. P.Smith, M. A. Adjuvant chemotherapy for stage II colon cancer with poor prognostic features. Journal of Clinical Oncology, 2011. 29: p. 3381-8.

9. Sallusto, F.Geginat, J.Lanzavecchia, A. Central memory and effector memory $\mathrm{T}$ cell subsets: function, generation, and maintenance. Annu Rev Immunol, 2004. 22: p. 745-63.

10. Castillo, J. J.Morales, D.Quinones, P.Cotrina, E.Desposorio, C.Beltran, B. Lymphopenia as a prognostic factor in patients with peripheral T-cell lymphoma, unspecified. Leuk Lymphoma, 2010. 51: p. 1822-8.

11. Manuel, M.Tredan, O.Bachelot, T.Clapisson, G.Courtier, A.Parmentier, G.Rabeony, T.Grives, A.Perez, S.Mouret, J. F.Perol, D.Chabaud, S.Ray-Coquard, I.et al., Lymphopenia combined with low TCR diversity (divpenia) predicts poor overall survival in metastatic breast cancer patients. Oncoimmunology, 2012. 1: p. 432-440.

12. Saroha, S.Uzzo, R. G.Plimack, E. R.Ruth, K.Al-Saleem, T. Lymphopenia is an Independent Predictor of Inferior Outcome in Clear Cell Renal Carcinoma. Journal of Urology, 2013. 189: p. 454-460.

13. Ceze, N.Thibault, G.Goujon, G.Viguier, J.Watier, H.Dorval, E.Lecomte, T.Pre-treatment lymphopenia as a prognostic biomarker in colorectal cancer patients receiving chemotherapy. Cancer Chemotherapy and Pharmacology, 2011. 68: p. 1305-1313.

14. Conesa, M. A. V.Garcia-Martinez, E.Billalabeitia, E. G.Benito, A. C.Garcia, T. G.Garcia, V. V.de la Pena, F. A. Predictive value of peripheral blood lymphocyte count in breast cancer patients treated with primary chemotherapy. Breast, 2012. 21: p. 468-474.

15. Camp, R. L.Dolled-Filhart, M.Rimm, D. L. X-tile: a new bio-informatics tool for biomarker assessment and outcomebased cut-point optimization. Clin Cancer Res, 2004. 10: p. $7252-9$.

16. Clark, E. J.Connor, S.Taylor, M. A.Madhavan, K. K.Garden, O. J.Parks, R. W. Preoperative lymphocyte 
count as a prognostic factor in resected pancreatic ductal adenocarcinoma. HPB (Oxford), 2007. 9: p. 456-60.

17. Feng, J. F.Liu, J. S.Huang, Y. Lymphopenia predicts poor prognosis in patients with esophageal squamous cell carcinoma. Medicine (Baltimore), 2014. 93: p. e257.

18. Kobayashi, N.Usui, S.Kikuchi, S.Goto, Y.Sakai, M.Onizuka, M.Sato, Y. Preoperative lymphocyte count is an independent prognostic factor in node-negative nonsmall cell lung cancer. Lung Cancer, 2012. 75: p. 223-227.

19. Mehrazin, R.Uzzo, R. G.Kutikov, A.Ruth, K.Tomaszewski, J. J.Dulaimi, E.Ginzburg, S.Abbosh, P. H.Ito, T.Corcoran, A. T.Chen, D. Y.Smaldone, M. C.Al-Saleem, T. Lymphopenia is an independent predictor of inferior outcome in papillary renal cell carcinoma. Urol Oncol, 2015 Sep;33:388.e19-25. doi: 10.1016/j.urolonc.2014.06.004. Epub 2014 Jul 11..

20. Zhang, J.Huang, S. H.Li, H.Li, Y.Chen, X. L.Zhang, W. Q.Chen, H. G.Gu, L. J. Preoperative lymphocyte count is a favorable prognostic factor of disease-free survival in nonsmall-cell lung cancer. Medical Oncology, 2013. 30(1).

21. Lissoni, P.Brivio, F.Fumagalli, L.Messina, G.Ghezzi, V.Frontini, L.Giani, L.Vaghi, M.Ardizzoia, A.Gardani, G. S. Efficacy of cancer chemotherapy in relation to the pretreatment number of lymphocytes in patients with metastatic solid tumors. Int J Biol Markers, 2004. 19: p. 135-40.

22. Balkwill, F.Mantovani, A. Inflammation and cancer: back to Virchow? Lancet, 2001. 357: p. 539-45.

23. Coussens, L. M.Werb, Z. Inflammation and cancer. Nature, 2002. 420: p. 860-7.

24. Jass, J. R.Love, S. B.Northover, J. M. A new prognostic classification of rectal cancer. Lancet, 1987. 1: p. 1303-6.

25. Ropponen, K. M.Eskelinen, M. J.Lipponen, P. K.Alhava, E.Kosma, V. M. Prognostic value of tumour-infiltrating lymphocytes (TILs) in colorectal cancer. J Pathol, 1997. 182: p. 318-24.

26. Ohtani, H.Naito, Y.Saito, K.Nagura, H. Expression of costimulatory molecules B7-1 and B7-2 by macrophages along invasive margin of colon cancer: a possible antitumor immunity? Lab Invest, 1997. 77: p. 231-41.

27. Menon, A. G.Janssen-van Rhijn, C. M.Morreau, H.Putter, H.Tollenaar, R. A.van de Velde, C. J.Fleuren, G. J.Kuppen, P. J. Immune system and prognosis in colorectal cancer: a detailed immunohistochemical analysis. Lab Invest, 2004. 84: p. 493-501.

28. Tormanen-Napankangas, U.Soini, Y.Paakko, P. High number of tumour-infiltrating lymphocytes is associated with apoptosis in non-small cell lung carcinoma. APMIS, 2001. 109: p. 525-32.

29. Chiba, T.Ohtani, H.Mizoi, T.Naito, Y.Sato, E.Nagura, H.Ohuchi, A.Ohuchi, K.Shiiba, K.Kurokawa, Y.Satomi, $\mathrm{S}$. Intraepithelial CD8+ T-cell-count becomes a prognostic factor after a longer follow-up period in human colorectal carcinoma: possible association with suppression of micrometastasis. Br J Cancer, 2004. 91: p. 1711-7.

30. Hiraoka, K.Miyamoto, M.Cho, Y.Suzuoki, M.Oshikiri, T.Nakakubo, Y.Itoh, T.Ohbuchi, T.Kondo, S.Katoh, H. Concurrent infiltration by CD8 $+\mathrm{T}$ cells and CD4+ T cells is a favourable prognostic factor in non-small-cell lung carcinoma. Br J Cancer, 2006. 94: p. 275-80.

31. Romano, F.Cesana, G.Berselli, M.Gaia Piacentini, M.Caprotti, R.Bovo, G.Uggeri, F. Biological, histological, and clinical impact of preoperative IL-2 administration in radically operable gastric cancer patients. J Surg Oncol, 2004. 88: p. 240-7.

32. Pages, F.Berger, A.Camus, M.Sanchez-Cabo, F.Costes, A.Molidor, R.Mlecnik, B.Kirilovsky, A.Nilsson, M.Damotte, D.Meatchi, T.Bruneval, P.Cugnenc, P. H.et al. Effector memory $\mathrm{T}$ cells, early metastasis, and survival in colorectal cancer. N Engl J Med, 2005. 353: p. 2654-66.

33. Kitayama, J.Yasuda, K.Kawai, K.Sunami, E.Nagawa, H. Circulating lymphocyte number has a positive association with tumor response in neoadjuvant chemoradiotherapy for advanced rectal cancer. Radiat Oncol, 2010. 5: p. 47.

34. Choi, C. H.Kim, W. D.Lee, S. J.Park, W. Y. Clinical predictive factors of pathologic tumor response after preoperative chemoradiotherapy in rectal cancer. Radiat Oncol J, 2012. 30: p. 99-107.

35. Murta, E. F.de Andrade, J. M.Falcao, R. P.Bighetti, S. Lymphocyte subpopulations in patients with advanced breast cancer submitted to neoadjuvant chemotherapy. Tumori, 2000. 86: p. 403-7.

36. Alkhouri, N.Morris-Stiff, G.Campbell, C.Lopez, R.Tamimi, T. A.Yerian, L.Zein, N. N.Feldstein, A. E. Neutrophil to lymphocyte ratio: a new marker for predicting steatohepatitis and fibrosis in patients with nonalcoholic fatty liver disease. Liver Int, 2012. 32: p. 297-302.

37. Sefil, F.Ulutas, K. T.Dokuyucu, R.Sumbul, A. T.Yengil, E.Yagiz, A. E.Yula, E.Ustun, I.Gokce, C. Investigation of neutrophil lymphocyte ratio and blood glucose regulation in patients with type 2 diabetes mellitus. J Int Med Res, 2014. 42: p. 581-8. 